\title{
The Relation between the Componding Time and the Viscoelastic Behavior of Rubber Compound
}

\author{
Somayyeh Mohammadian* and Abbas Khoshal \\ Payame Noor University, Iran \\ *Corresponding author: Somayyeh Mohammadian, Payame Noor University, Tehran, Iran.
}

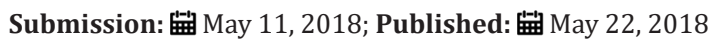

\begin{abstract}
The relation between mixing time and the viscoelastic properties of a Rubber polymeric compound was investigated through samplings in various mixing times and analyzing by a dynamic mechanical rheological tester and. The obtained results were compared with the torque variations during mixing time in the internal mixer. The changes in the shear elastic modulus ( $\left.G^{\prime}\right)$ at low strain amplitude were similar to the torque behavior in the internal mixer before and after Black Incorporation Time (BIT). The photographs at various steps of mixing were taken by Disperse Grader. It was found that the mixing characteristics can be predicted using $G^{\prime}$ and the torque of mixing simultaneously. The changes in $G^{\prime}$ and damping factor versus frequency were studied as well.
\end{abstract}

Keywords: Rubber; Compounding; Disperse grader; Shear elastic modulus; Damping factor

\section{Introduction}

The important instruments to study the viscoelastic properties of the polymers are the torsional dynamic rheometers. In these equipments a sinusoidal strain is applied in order to assess the resulting complex stress of the material. The viscoelastic response is out phase with respect to the applied strain. Both the measured complex stress and the phase angle relate directly to the viscoelastic properties of the material [1]. Advances in mixing process and the concern with the quality of raw materials; have resulted in a significant improvement in the quality and consistency of mixed compound [2].

The aim of mixing process is to produce a homogenate compound that has the uniform dispersion of ingredients to give the required properties for the application. There are four physical steps during the mixing cycle: incorporation; dispersion; distribution; and plasticization. This is especially important in the case of carbon black; because at this stage an intimate contact between the surface of the carbon black and elastomer are developed; resulting in bound rubber. In the next step the various ingredients are randomly distributed throughout mass of the mixture and in the final stage of mixing the rheological properties are modified to suit subsequent operations [3,4]. On the other side; the viscoelastic behavior is an important key in the polymeric materials; especially rubber compounds [4,5]. In this work a black filled rubber compound based on styrene-butadiene rubber (SBR) was prepared using an internal mixer. The dispersion of carbon black in compound at various steps of mixing was studied using disperse grader images. In addition the quality of mixing was investigated by measuring G' via RPA and the results compared with the torque variations during mixing.

\section{Experimental}

\section{Materials}

The master formulation of a tire tread compound based on styrene-butadiene rubber was prepared in this study. The materials which used as the ingredients and the formulation of the sample are shown in Table 1.

Table 1: Master formulation of tire tread compound.

\begin{tabular}{|c|c|c|}
\hline Ingredients & Phr & Comments \\
\hline SBR 1500 & 37 & BIPC Co. \\
\hline SBR 1712 & 86.6 & BIPC Co. \\
\hline Black N115 & 15 & Doodeh Pars Co. \\
\hline Black N375 & 63 & Doodeh Pars Co. \\
\hline ZnO & 3.1 & Rangineh Pars Co. \\
\hline Stearic Acid & 2.5 & Unichema International Co. \\
\hline Micro Crystaline Wax & 1.25 & Unichema International Co. \\
\hline 6PPD & 1.25 & Vulkanox 4020, Bayer Co. \\
\hline Aromatic Oil & 14 & Behran Oil Co. \\
\hline
\end{tabular}




\section{Instruments}

The filled rubber compound was mixed using the SYS 90 HIB internal mixer from HAAKE Company. During mixing process; the temperature and rotor speed can be controlled and torque value is reported by mixing time. A Rubber Process Analyzer (RPA 2000) from Alpha Co. was used to investigate the viscoelastic properties. The photographs of carbon black dispersion were taken by Disperse Grader (DisperGrader 1000NT) at the magnification of 100 times.

\section{Test method}

The compounds were prepared in the laboratory internal mixer at temperature of $100{ }^{\circ} \mathrm{C}$ and different rotor speeds of 40 and 80rpm. Mixing carried out at different mixing times. First; the rubber was fed into the chamber and masticated for 30 second; then carbon black and other ingredients were added; respectively. Finally; the rotors were stopped and the samples were taken out and then were stored for 24 hours to relax the mixing stresses. The mixing quality (dispersity) was considered using Disperse Grader. To measure the viscoelastic parameters of samples; RPA 2000 was used within the linear viscoelastic region. In this case the frequency sweep tests were done at $1 \%$ strain; $100{ }^{\circ} \mathrm{C}$ temperature and the frequency domain of $0.1-100 \mathrm{rad} / \mathrm{sec}$ was done.

\section{Results and Discussion}

Figure 1 expresses the torque time curve of the mixer schematically and Figure 2 shows the photographs of carbon black dispersion (as the white particles) at several mixing times which is related to the marked points of Figure 1. As the photographs show in Figure 2; for mixing times larger than BIT (C; D and E) dispersity is improved and with increasing the mixing time; distribution of carbon black was progressed. As expected; deformation of elastomeric and breaking down into the small pieces and finally dispersion are taken place during the BIT and then; carbon black distribution in the rubber is begun. At the end of the BIT; torque reaches a maximum value and then decreases gradually until it gets a plateau [6]. The agglomerates of carbon black are clearly observed in image (2A). With increasing the mixing time these agglomerates are broken down and wetting occurs. In the final photograph; a good dispersion of carbon black in the rubber matrix can be seen.

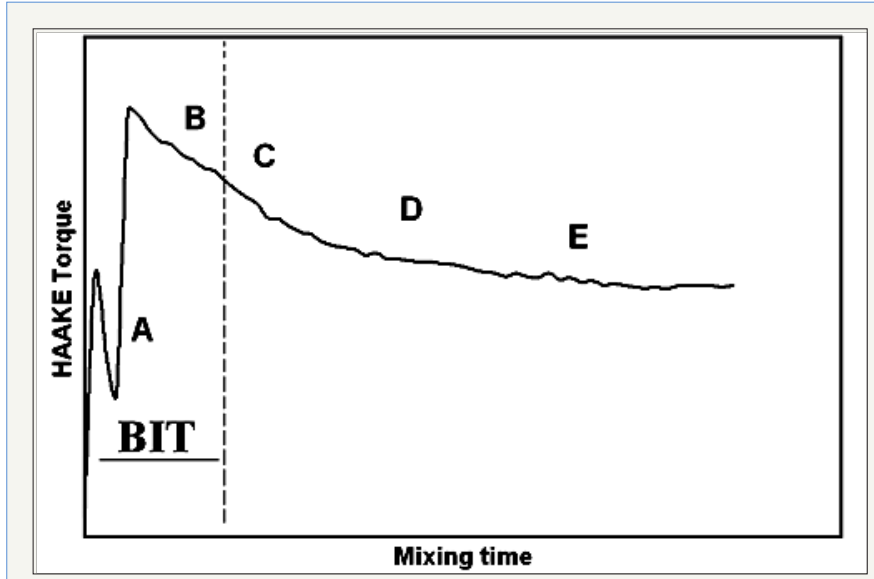

Figure 1: Schematic torque-time curve of mixer.

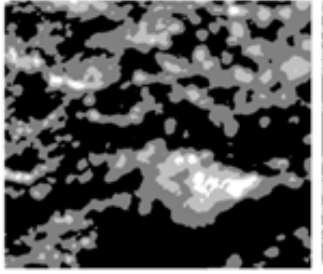

A

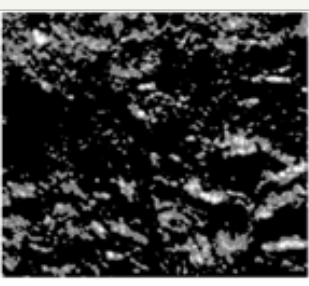

B Increasing Compounding time

Figure 2: Photographs of carbon dispersion at mixing intervals related to the marked points of Figure 1 (magnification of 100 times).

\section{RPA Results}

The complex dynamic shear modulus $\mathrm{G}^{*}$ divided to the elastic and viscosity modulus ( $\mathrm{G}^{\prime}$ and $\mathrm{G}^{\prime \prime}$ ) by the equation (1) [7].

$$
G^{*}=\sqrt{\left(G^{\prime 2}+G^{\prime \prime 2}\right)}
$$

To study the changes of $G^{\prime}$ with the mixing time; samples were taken out from the internal mixer and were tested using RPA. The results of the frequency sweep tests are shown in Figure 3. As can be seen; the compounds which have prepared at different mixing times have the same trend. The frequency sweep results can be use to plot $G^{\prime}$ curve versus mixing time at a certain frequency. Figure 4 shows the variation of $G^{\prime}$ against mixing time at the constant frequency of $1 \mathrm{rad} / \mathrm{sec}$. As can be seen before the BIT; G' curve shows two maximums and then decreases and reaches to a plateau or constant value. This curve has an interest similarity to the torque curve versus mixing time during mixing.

The variation of torque and G' can be explained by different steps of mixing process. The torque value of the mixer during mixing; relates directly to the elastic modulus of the compound. In fact; elastic modulus is an effective factor on the required shear force for mixing. Thus it is expected that the measured torque and the elastic modulus have the same behaviour with mixing time. Consequently the mixing quality can be explained by G' using frequency sweep test from RPA. 


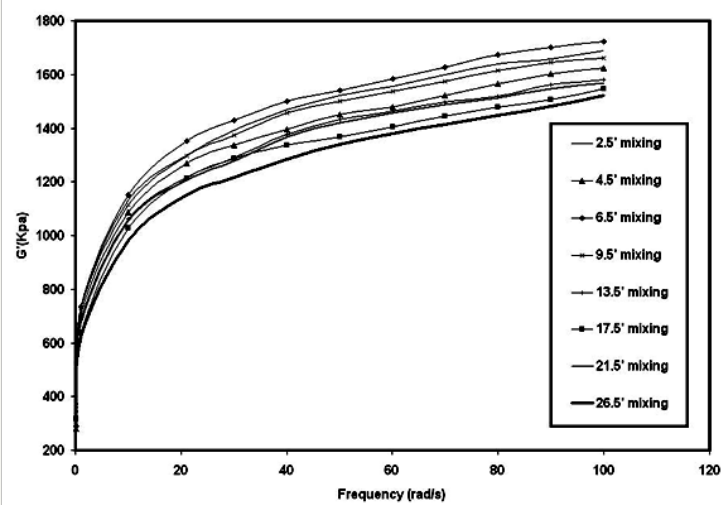

Figure 3: Variations of storage modulus with frequency at various mixing times.

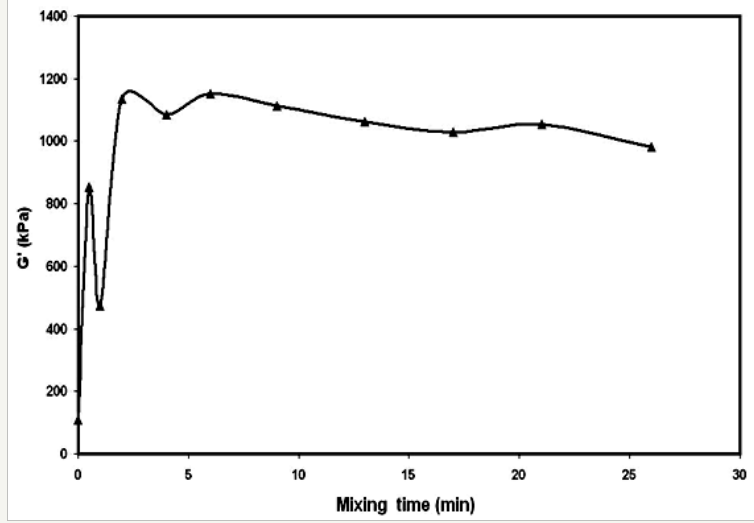

Figure 4: Elastic modulus versus mixing time at frequency of $1 \mathrm{rad} / \mathrm{sec}$.

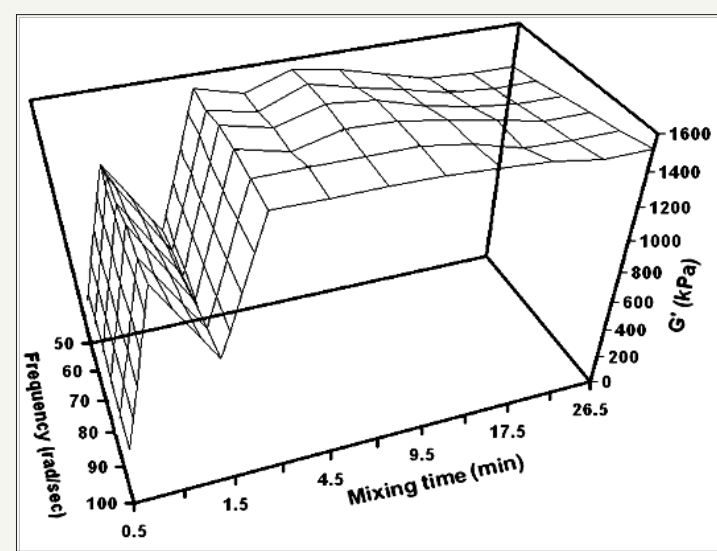

Figure 5: The influence of mixing time on the elastic modulus at different frequencies.

Figure 5 expresses the influence of mixing time on the elastic modulus at different frequencies. Regarding to Figure 3; at the frequencies higher than $50 \mathrm{rad} / \mathrm{sec}$; the changes of $\mathrm{G}^{\prime}$ is negligible. Therefore; to compare the mixing time effect; larger frequencies data selected to draw Figure 5. This graph exhibits the same trend of G' variation such as Figure 4 for all frequencies. The ratio of viscous component ( $\left.G^{\prime \prime}\right)$ to the elastic component $\left(G^{\prime}\right)$ of the material is introduced by damping factor; $\tan \delta$; as equation (2).

$$
\tan \delta=G^{\prime \prime} / G^{\prime}
$$

In Figure 6; $\tan \delta$ was plotted against frequency at a constant mixing time. It can be observed that with increasing the frequency; $\tan \delta$ decreases and then reaches a plateau zone. This plateau shows that the ratio of viscous response to the elastic response of the compound is constant in a wide frequency domain which confirms that the RPA results are in the linear region and reliable.

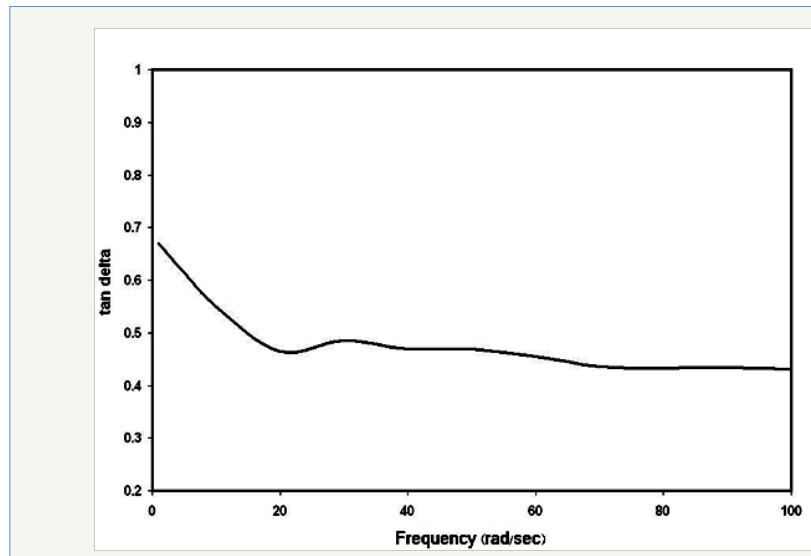

Figure 6: Changes in $\tan \delta$ with frequency at 6.5 minutes mixing time.

\section{Conclusion}

The effect of mixing time on the mixing quality and carbon black dispersion of a filled rubber compound was investigated. Samples based on tire tread formulation were prepared at several mixing times. Disperse Grader photographs obviously recognized the different steps of mixing and the influence of mixing time on carbon black dispersion. The results of frequency sweep tests from RPA were compared with the torque-time curve of the internal mixer during mixing. The elastic modulus versus mixing time; at first showed two peaks and after passing the BIT decreased and reached a plateau. This variation is similar to the torque behaviour of the internal mixer during mixing.

\section{References}

1. Darley HCH, George GR (1988) Composition and properties of drilling and composition fluids. $\left(5^{\text {th }}\right.$ edn), Gulf professional publishing, Texas, USA.

2. Lummus JL, Barrett HM, Allen H (1953) The effects of use of oil in drilling muds. API Drill Prod Prac, pp. 135-145.

3. Mahto V, Sharma VP (2009) Tragacant gum: an effective oil well drilling fluid additive. Energy Sources 27(3): 299-308.

4. Bird RB, Dai GC, Yarusso BY (1982) The rheology and flow of viscoplastic materials. Rev Chem Eng 1(1): 1-70.

5. Kok MV, Gucuyener IH, Batmaz T (2002) End effect evaluation in rheological measurement of drilling fluids using couette coaxial cylinder viscometer. Energy Source 24(5): 441-449.

6. Kok MV, Batmaz T, Gucuyener IH (2000) Rheological behavior of bentonite suspensions. Pet Sci Tech 18(5-6): 519-536.

7. Borg T, Paakkonen EJ (2015) Linear viscoelastic model for different flows based on control theory. Appl Rheol 25(6). 
8. Kelessidis VC, Maglione R (2006) Modeling rheological behavior of bentonite suspensions as casson and robertson-stiff fluids using newtonian and true shear rates in couette viscometry. Powder Technol 168(3): 134-147.

9. Kelessidis VC, Maglione R, Tsamantaki C, Aspirtakis Y (2006) Optimal determination of rheological parameters for herschel-bulkley drilling fluids and impact on pressure drop, velocity profiles and penetration rates during drilling. J Pet Sci Eng 53(3-4): 203-224.

10. Saasen A, Omland TH, Ekrene S, Breviere J, Villard E, et al. (2009) Automatic measurement of drilling fluid and drill-cuttings properties. Society of Petroleum Engineers 24(4).
11. Ahmed R, Miska S (2009) Advanced wellbore hydraulics. In: Aadnoy BS (Ed.), Advanced drilling and well technology. Society of Petroleum Engineers, USA, pp. 191-219.

12. Xu JY, Wu YX, Li H, Guo J, Chang Y (2009) Study of drag reduction by gas injection for power-law fluid flow in horizontal stratified and slug flow regimes. Chem Eng J 147(2-3): 235-244.

13. Ashrafizadeh SN, Kamran M (2010) Emulsification of heavy crude oil in water for pipeline transportation. J Pet Sci Eng 71(3-4): 205-211.
Creative Commons Attribution 4.0 International License

For possible submissions Click Here
Submit Article

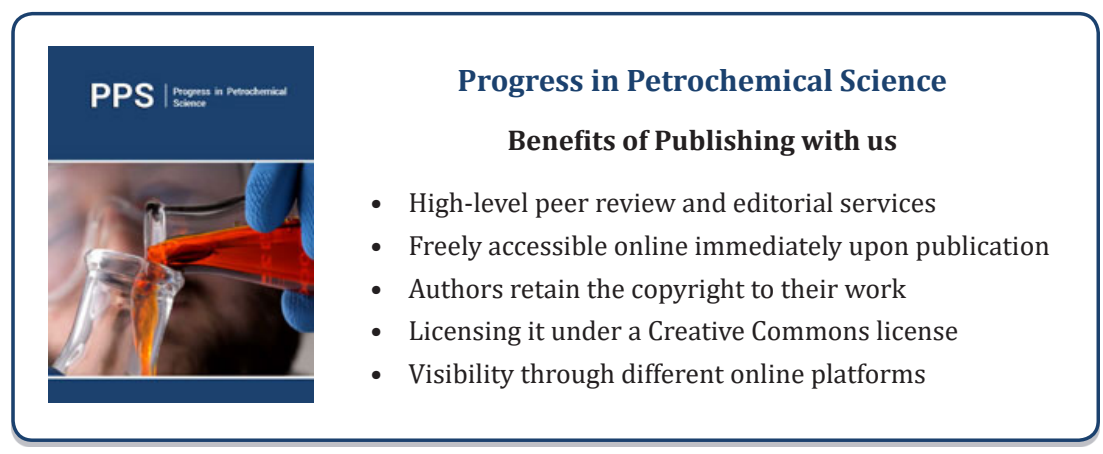

